\title{
Hybridization between crops and wild relatives: the contribution of cultivated lettuce to the vigour of crop-wild hybrids under drought, salinity and nutrient deficiency conditions
}

\author{
Brigitte Uwimana $\cdot$ Marinus J. M. Smulders • Danny A. P. Hooftman • \\ Yorike Hartman • Peter H. van Tienderen • Johannes Jansen • Leah K. McHale • \\ Richard W. Michelmore • Clemens C. M. van de Wiel • Richard G. F. Visser
}

Received: 3 November 2011 / Accepted: 11 May 2012/Published online: 4 June 2012

(C) The Author(s) 2012. This article is published with open access at Springerlink.com

\begin{abstract}
With the development of transgenic crop varieties, crop-wild hybridization has received considerable consideration with regard to the potential of transgenes to be transferred to wild species. Although many studies have shown that crops can hybridize with their wild relatives and that the resulting hybrids may show improved fitness over the wild parents, little is still known on the genetic contribution of the crop parent to the performance of the hybrids. In this study, we investigated the vigour of lettuce
\end{abstract}

Communicated by T. Close.

Electronic supplementary material The online version of this article (doi:10.1007/s00122-012-1897-4) contains supplementary material, which is available to authorized users.

B. Uwimana $(\bowtie) \cdot$ M. J. M. Smulders .

C. C. M. van de Wiel - R. G. F. Visser

Wageningen UR Plant Breeding, Wageningen, The Netherlands

e-mail: brigumbu@gmail.com

C. C. M. van de Wiel

e-mail: clemens.vandewiel@wur.nl

D. A. P. Hooftman

Centre for Ecology and Hydrology, Wallingford, UK

Y. Hartman · P. H. van Tienderen

IBED, Universiteit van Amsterdam,

Amsterdam, The Netherlands

J. Jansen

Wageningen UR Biometris, Wageningen, The Netherlands

L. K. McHale

Department of Horticulture and Crop Science,

Ohio State University, Columbus, USA

R. W. Michelmore

Genome Center, University of California Davis, Davis, USA hybrids using $98 \mathrm{~F}_{2: 3}$ families from a cross between cultivated lettuce and its wild relative Lactuca serriola under non-stress conditions and under drought, salinity and nutrient deficiency. Using single nucleotide polymorphism markers, we mapped quantitative trait loci associated with plant vigour in the $\mathrm{F}_{2: 3}$ families and determined the allelic contribution of the two parents. Seventeen QTLs (quantitative trait loci) associated with vigour and six QTLs associated with the accumulation of ions $\left(\mathrm{Na}^{+}, \mathrm{Cl}^{-}\right.$and $\mathrm{K}^{+}$) were mapped on the nine linkage groups of lettuce. Seven of the vigour QTLs had a positive effect from the crop allele and six had a positive effect from the wild allele across treatments, and four QTLs had a positive effect from the crop allele in one treatment and from the wild allele in another treatment. Based on the allelic effect of the QTLs and their location on the genetic map, we could suggest genomic locations where transgene integration should be avoided when aiming at the mitigation of its persistence once crop-wild hybridization takes place.

\section{Introduction}

Gene flow between crop species and their wild relatives may result in the introgression of crop genes into wild genomic background, or in the formation of new species through novel combinations of crop and wild genes (Burke and Arnold 2001; Hails and Morley 2005). The possibility of hybridization between transgenic crops and their wild relatives has brought interest on crop-wild gene flow to another level due to the potential ecological consequences of the possibility that transgenes could also be introgressed into wild populations (Tiedje et al. 1989; Hall et al. 2000; Snow et al. 2005; Warwick et al. 2009; Wilkinson and Tepfer 2009). 
Gene flow can lead to hybrid plants containing crop alleles. Crop alleles subsequently have a higher likelihood of becoming established in the population of the wild relative with few crop-wild hybridization events, when they provide a selective advantage to the fitness of the hybrid plants and their offspring than when they are selectively neutral (Lee and Natesan 2006). In the introgression and speciation processes, the unit of selection in the first generations of hybrids is not the crop gene as such, but genomic blocks from the crop consisting of the gene under selection and the surrounding linked genomic region (Stewart et al. 2003). Consequently, linkage between genes plays a crucial role in the introgression process, because a gene (or transgene) that has no effect on fitness may become introgressed just by hitchhiking along with a gene that increases fitness. Conversely, a (trans)gene could be selected against due to its proximity to a gene that reduces fitness. Such linkage would provide a natural mechanism against introgression and escape of transgenes into wild populations (Stewart et al. 2003; Kwit et al. 2011).

Multiple studies have focused on the rate of hybridization between crops and wild relatives (Arias and Rieseberg 1994; Hoc et al. 2006; D’Andrea et al. 2008; Giannino et al. 2008; Kiær et al. 2009), and on the occurrence of hybrids and their fitness in relation to the fitness of the wild parent (Snow et al. 2003; Hooftman et al. 2005, 2009; Campbell and Snow 2007). However, few studies have been conducted with the aim of understanding the specific contribution of the crop and wild parents to the fitness of the hybrids, the role of the genomic locations of the genes (as for instance assessed through quantitative trait loci (QTL), Baack et al. 2008), and the role of epistasis and genotype by environment interaction on the fitness or vigour of the hybrids. The combination of synthetic mapping populations and genetic linkage maps provides an excellent tool for studying the introgression process in an experimental setup. It allows the determination of QTLs affecting hybrid vigour or fitness, estimation of the contribution of each parent to the performance of the offspring under controlled or non-controlled conditions and monitoring of specific genomic blocks in different generations after hybridization (Rieseberg et al. 2000; Burke and Arnold 2001; Stewart et al. 2003; Baack et al. 2008).

In this study, we investigated the contribution of the crop alleles to the performance of a crop-wild hybrid population derived from a cross between cultivated lettuce (Lactuca sativa L.) and wild prickly lettuce (Lactuca serriola L.). Cultivated lettuce and wild prickly lettuce are interfertile species, the hybrids of which are viable and fertile (Lindqvist 1960; Ryder and Whitaker 1976; De Vries 1990). Experiments have shown that lettuce cropwild hybrids are more vigorous than their parents (Hooftman et al. 2005, 2007) and that this increased vigour may lead to improved fitness of their offspring (Hooftman et al. 2009). In this study, we investigated the genetic basis of improved hybrid vigour of lettuce hybrid plants at the rosette stage. When drawing conclusions on fitness in wild populations, studies following plants during a complete cycle from seed to seed would be most optimal. However, early life stages of plants such as germination, seedling stage and vegetative growth are crucial phases as they determine the survival and reproduction of the plant, especially under stress conditions (Foolad 1996; Albacete et al. 2008; Donohue et al. 2010). In lettuce crop-wild hybrids, selection takes place on young plants, leading to surviving lineages with higher vigour and fitness than the wild genotypes (Hooftman et al. 2005, 2009). Therefore, studies of young plants could already give valuable clues on crop-wild hybrid fitness in an efficient manner through performing relatively short experiments under controlled conditions. Under natural conditions, the hybrids will most likely be subject to adverse conditions of abiotic stress such as drought, heat, cold, etc. Tolerance to abiotic stress factors is a prominent goal of today's GM breeding and evaluation, and the release of GM crop varieties tolerant to the major abiotic stress is expected in the near future for many crop species (Castiglioni et al. 2008; Abdeen et al. 2010; Li et al. 2010; Choi et al. 2011). Therefore, we conducted experiments under controlled abiotic stress conditions of drought, salinity and nutrient deficiency in the $F_{2}$ progeny of a cross between $L$. sativa and $L$. serriola. We addressed the following questions: (1) how is the performance of the hybrids relative to the wild parent under non-stress and stress conditions? (2) Do crop alleles contribute an advantage or disadvantage to the crop-wild hybrids under non-stress and abiotic stress conditions (drought, salinity and nutrient deficiency)? (3) How are the vigour QTLs distributed along the genome, and what is the nature of their allelic effects?

\section{Materials and methods}

\section{Lactuca serriola and L. sativa}

Lactuca serriola, prickly lettuce, is a weedy species that thrives in ruderal, anthropogenic areas (Lebeda et al. 2001). It is the closest relative of cultivated lettuce ( $L$. sativa) with which it could even be considered to be conspecific (Kesseli et al. 1991; Hill et al. 1996; Koopman et al. 1998). The two species have the same number of chromosomes $(2 n=2 x=18)$, are completely cross-compatible and the resulting hybrids are also viable and fertile (Lindqvist 1960; Ryder and Whitaker 1976; De Vries 1990). L. serriola and L. sativa therefore constitute a classic cropweed complex perfect for introgression studies. Both 
species are basically autogamous, but with a limited rate of out-crossing by insects of 1 to $5 \%$ for L sativa (Thompson et al. 1958) and an interspecific hybridization rate of up to $2.5 \%$ between the two species (D'Andrea et al. 2008). A recent large-scale population genetic study has shown the occurrence of spontaneous hybrids in the field in Europe (Uwimana et al. 2012a).

\section{Development of hybrid plants}

$\mathrm{F}_{1}$ progeny was created by crossing $L$. serriola and $L$. sativa in the greenhouse. The L. serriola parent was a progeny of a plant collected from Eys (Province of Limburg, The Netherlands), and it represents a commonly occurring genotype among $L$. serriola in northwestern and Middle Europe (designated as "cont83" in Van de Wiel et al. 2010). For the L. sativa parent, we used the commercial cultivar Dynamite, a butterhead lettuce developed by Nunhems Zaden. It harbours genes for resistance to aphids, downy mildew and lettuce mosaic virus (Van der Arend et al. 1999), which represent important breeding goals of lettuce cultivars. L. sativa was used as the pollen donor, mimicking a scenario of pollen flow from a crop to its wild relative. Crossing was performed according to the protocols by Nagata (1992) and Ryder (1999) as described in Hooftman et al. (2005). $F_{2}$ seeds were produced by selfing of one $F_{1}$ plant. $F_{2}$ seeds were sown and 200 seedlings were randomly chosen, transplanted and genotyped as described below. The plants were selfed and the resulting $\mathrm{F}_{3}$ seeds were harvested per individual $\mathrm{F}_{2}$ plant.

Genotyping and construction of the linkage map

The Compositae Genome Project at UC Davis Genome Center has developed single nucleotide polymorphism (SNP) markers from lettuce populations derived from crosses between closely related cultivars of L. sativa and between $L$. sativa and L. serriola. These SNPs were mined initially by re-sequencing PCR-amplified genes of interest between Lactuca sativa cv. Salinas and L. serriola acc. UC96US23 using Sanger sequencing (McHale et al. 2009) and by mining Illumina sequencing data aligned to reference EST assemblies (http://compgenomics.ucdavis.edu/ compositae_SNP.php). cDNA libraries from parental lines were sequenced with Illumina Genome Analyzer II. These ESTs sequences encode genes for disease resistance and plant development. In this way, more than 10,000 SNPs were developed from 3,950 ESTs in four parental pair combinations, namely Salinas $\times$ Valmaine, Pavane $\times$ Parade, Emperor $\times$ El Dorado and Thompson $\times$ Cisco (http://compgenomics.ucdavis.edu/compositae_SNP.php). To improve the conversion success rate of bio-informatically identified SNPs to molecular markers, potential SNPs were filtered to 1,083 SNPs that had been previously assayed and shown to be robust, were polymorphic in more than one of the four parental pair combinations, were not located in intron/exon splice sites, were limited to one SNP per contig, were candidate genes of interest, were evenly distributed based on previous mapping work and the ultradense lettuce map, and for which the surrounding sequence was suitable for oligonucleotide design for the Illumina GoldenGate assay. The selected 1,083 SNPs were converted into Custom GoldenGate Panels (OPA) for genotyping, using an Illumina BeadXpress assay. From the 1,083 SNPs, a customized OPA of 384 SNPs which were polymorphic between the $\mathrm{F}_{2}$ parental lines was made specifically for the population.

DNA was extracted from freeze-dried leaf samples of the $200 \mathrm{~F}_{2}$ and parent lines using the QIAGEN DNeasy 96 Plant Kit (QIAGEN, Venlo, The Netherlands) with slight modifications for dry plant tissue to obtain a minimum DNA concentration of $60 \mathrm{ng} / \mu \mathrm{l}$. The DNA concentration was quantified using a NanoDrop 1000 Spectrophotometer V3.7 (Thermo Scientific). We genotyped $187 \mathrm{~F}_{2}$ individuals and the parents using the customized 384 SNP OPA in a BeadXpress assay. Out of the 384 SNPs, 355 were successfully scored in the $187 \mathrm{~F}_{2}$ and parental lines. 331 Markers were co-dominant, 16 were dominant for the L. serriola allele and 8 were dominant for the $L$. sativa allele. The genotypes for the $187 \mathrm{~F}_{2}$ individuals were used to build a genetic linkage map using JoinMap ${ }^{\circledR} 4$ (Van Ooijen 2006). Segregation distortion was tested against the expected allele frequency ratio of $1: 1$, using the $\chi^{2}$ test of goodness of fit with one degree of freedom. Markers within linkage groups were ordered using the maximum likelihood option of JoinMap (Jansen et al. 2001). The linkage map was displayed using MapChart 2.2 (Voorrips 2002).

\section{Greenhouse experiments}

Based on the genotypes of the $187 \mathrm{~F}_{2}$ individuals, we selected a set of $98 \mathrm{~F}_{2}$ plants that optimized the number of different combinations of parental haplotype blocks, using the program "Genetic Distance Optimization" (GDOpt) (Odong et al. 2011). The program uses adapted $K$-medoids clustering (Kaufman and Rousseeuw 1990) in which one individual in each of the $K$ clusters acts as cluster centre and clusters are formed by minimizing the total distance of all individuals to the nearest of the $K$ individuals designated as cluster centres. In order to obtain a good starting point, the initial configuration of cluster centres was provided by a modified version of Genetic Distance Sampling (Jansen and van Hintum 2007).

$\mathrm{F}_{2: 3}$ families were derived from the genotyped $\mathrm{F}_{2}$ plants by selfing, and these were used together with the parents of the cross in greenhouse experiments in Wageningen, The 
Netherlands. To the experimental lines, we added two additional lines, $L$. serriola acc. UC96US23 and $L$. sativa cv. Salinas, which, together with the parental lines, were later used to estimate the environmental error. We carried out two experiments: (1) the "drought experiment" (March-April 2010), which comprised drought and control treatments and (2) the "salt-nutrient experiment" (JuneJuly 2010), which comprised salt, nutrient deficiency and control treatments. Each $\mathrm{F}_{2}$ plant was represented by 12 $\mathrm{F}_{2: 3}$ seedlings per treatment. The parents and the two additional lines were also replicated 12 times per treatment.

During first establishment, the seedlings were irrigated twice a week for 2 weeks with water supplemented with nutrients. Subsequently, the treatments were started at the beginning of the third week after transplanting of the seedlings, when the plants had four to five leaves. For the drought experiment, the plants in the control treatment were still watered twice a week, while the plants in the drought treatment were not given water at all. For the saltnutrient experiment, the plants were again irrigated twice a week, but with added $100 \mathrm{mM}$ of $\mathrm{NaCl}$ in the irrigation water. The plants under nutrient deficiency treatment received water to which no nutrients were added. The control plants received nutrients for the whole period of the experiment. Stress was applied for 3 weeks after which time the plants were harvested at the rosette stage, 35 days after transplanting. A photoperiod of $18{ }^{\circ} \mathrm{C} / 16 \mathrm{~h}$ of light and $15{ }^{\circ} \mathrm{C} / 8 \mathrm{~h}$ of darkness was maintained throughout the experiments by temperature control and application of artificial lighting as needed. However, high summer temperatures influenced the greenhouse conditions during the salt-nutrient experiment when outside temperature reached as high as $35^{\circ} \mathrm{C}$.

\section{Phenotypic measurements}

For each plant, vigour was determined by fresh and dry shoot biomass and shoot height. Vigour can be taken as a proxy for fitness at this young growth stage, but under the caveat that fitness could only be comprehensively assessed by following plants during a whole cycle from seed to seed. Shoot dry weight was measured after these were dried at $80{ }^{\circ} \mathrm{C}$ for 3 days. We also calculated shoot relative moisture content as the ratio of the amount of water in the shoot to the total shoot weight [(fresh weight - dry weight) $\times 100 /$ fresh weight]. The ion content $\left(\mathrm{Na}^{+}, \mathrm{K}^{+}\right.$, and $\left.\mathrm{Cl}^{-}\right)$ for salt and control treatments of the salt-nutrient experiment was measured. Because ion content is measured based on dry matter, the $80{ }^{\circ} \mathrm{C}$-dried shoots were dried again at $100{ }^{\circ} \mathrm{C}$ for $24 \mathrm{~h}$. The 12 plants per line per treatment were pooled, ground to fine powder, well mixed, and about $30 \mathrm{mg}$ of dry matter was measured with the precise weight recorded. The ground samples were ashed at
$545{ }^{\circ} \mathrm{C}$ for $5 \mathrm{~h}$, diluted in $3 \mathrm{M}$ formic acid and further diluted 1,000 times with extra-pure water. The diluted solutions were used in ion chromatography analysis on an 881 Compact IC pro (Metrohm AG, Herisau, Switzerland, Stolte et al. 2011).

Analysis of phenotypic data

Statistical analysis was performed using GenStat 13 (Payne et al. 2011). Drought and salt-nutrient experiments were analysed separately. The significance of the different terms was determined by the analysis of variance, fitting the model:

$$
\begin{aligned}
\text { Response }= & \text { general mean }+ \text { block }+ \text { genotype } \\
& + \text { treatment }+ \text { genotype } \times \text { treatment }+ \text { error }
\end{aligned}
$$

Broad sense heritability of family means of the traits was estimated for each treatment separately as the proportion of the total variance accounted for by the genetic variance using the formula

$H^{2}=V_{\mathrm{g}\left(\mathrm{F}_{2}\right)} /\left(V_{\mathrm{g}\left(\mathrm{F}_{2}\right)}+V_{\mathrm{e}} / r\right)$;

where $V_{\mathrm{g}\left(\mathrm{F}_{2}\right)}$ is the genetic variance among $\mathrm{F}_{2: 3}$ families, $V_{\mathrm{e}}$ is the environmental variance, and $r$ is the number of replications (Chahal and Gosal 2002). $V_{\mathrm{g}\left(\mathrm{F}_{2}\right)}$ was estimated based on the restricted maximum likelihood (REML) method from the mixed model:

Response $=$ general mean + block $+F_{2}$ genotype + error;

with the response term representing the measured traits, and the term $\mathrm{F}_{2}$ genotype taken at random. $V_{\mathrm{e}}$ was the error variance derived from a one-way analysis of variance of the model:

Response $=$ general mean + block + parents + error;

with the term parents representing the two parents of the $\mathrm{F}_{2}$ plants and the two added lines (L. serriola acc. UC96US23 and $L$. sativa cv. Salinas).

\section{Quantitative trait loci (QTLs) analysis}

In order to effectively model genotype by environment interaction $(\mathrm{G} \times \mathrm{E}$, with environments represented by the different treatments) through QTL by environment interaction $(\mathrm{QTL} \times \mathrm{E})$, each trait was analysed individually using the single trait-multiple environment option of the programme. Genome-wide association between markers and traits was decided based on a significance level of 0.05 corrected for multiple tests using the $\mathrm{Li}$ and $\mathrm{Ji}$ method ( $\mathrm{Li}$ and Ji 2005). After the selection of the best variancecovariance model for the treatments (Malosetti et al. 2004), the candidate QTLs were determined by an initial genome 
scan. Final QTL positions were determined by composite interval mapping taking into account co-factors. The allelic effect of the detected QTLs in each treatment, the effect of QTL $\times$ E and the explained phenotypic variance of each QTL per treatment were determined by running a backward selection on the candidate QTLs in a mixed linear model, taking the QTL effect in each treatment as fixed terms and the interaction between each hybrid family and the treatment as random (Mathews et al. 2008). In that way, each QTL detected in one treatment was tested for its effect and significance in the other treatments.

Epistasis was tested for the detected QTLs (Holland 2007). Each QTL region was represented by the genotypic scores of the most significant marker in a multiple regression model in GenStat. To avoid the effect of linkage, overlapping QTLs were represented by one SNP marker and no interaction was estimated for QTLs on the same linkage group even if they did not overlap. In each treatment, every trait was explained by the main effects of all the detected QTLs to which interaction between one pair of QTLs was added at a time. QTL $\times$ QTL interaction was decided significant at a level of 0.05 , which was corrected for the number of traits by the Bonferroni method (Bland and Altman 1995).

\section{Results}

\section{Phenotypic variation}

The analysis of variance revealed significant genotypic variation for the measured vigour traits (plant height, fresh weight, dry weight and relative moisture content; $P_{\text {genotype }}$ $<0.001)$, and there was significant genotype $\times$ treatment variation $\left(P_{\text {genotype }} \times\right.$ treatment $\left.<0.001\right)$. Broad sense heritability of family means of the traits ranged from moderate to high $\left(0.51 \leq H^{2} \leq 0.99\right.$, Table 1$)$, showing that the phenotypic variation among the $F_{2: 3}$ families was mainly explained by genetic factors. Heritability depended on the treatment. Plant height and relative moisture content seem to show similar heritability under controlled and stressed conditions. For the weight traits (both fresh and dry), however, heritability is consistently lower for all the stressed conditions and particularly so for drought and nutrient deficiency. Crop-wild hybridization released genetic variance: even when the means of the parents were not significantly different, heritability was relatively high as observed for dry weight under control $\left(H^{2}=0.90\right)$ and drought conditions $\left(H^{2}=0.66\right)$ and for relative moisture content under nutrient deficiency conditions $\left(H^{2}=0.89\right)$ (Table 1).
For each trait and under all the treatments, there were $\mathrm{F}_{2: 3}$ individuals whose measurements were equal to or greater than the means of the two L. serriola lines (Online Resource 1). In addition, the mean for the $L$. serriola parent always fell within the range of the minimum and maximum values of the $\mathrm{F}_{2: 3}$ families for all the traits and under all the treatments (Table 1). Therefore, among the crop-wild lettuce hybrid families, there clearly are a relevant number of examples having potentially increased vigour in comparison to the wild parent under the four tested conditions (non-stress, drought, salt and nutrient deficiency conditions).

Plant height positively correlated with biomass, except under salt treatment where fresh weight was negatively correlated with plant height $(r=-18$, Table 2). Under salt treatment, $\mathrm{Na}^{+}, \mathrm{Cl}^{-}$and $\mathrm{K}^{+}$negatively correlated with plant height. The correlation between ion content and plant biomass was apparently due to shoot moisture content as $\mathrm{Na}^{+}$and $\mathrm{Cl}^{-}$positively correlated with fresh weight and relative moisture content, but did not correlate with dry weight $\left(r=0.03\right.$ for $\mathrm{Na}^{+}$and $r=0.07$ for $\left.\mathrm{Cl}^{-}\right)$. The lack of correlation between ion content and dry weight indicates that the accumulation of ions in the shoots is not related to the biomass of the plants under salt treatment.

\section{Genotypic data}

The linkage map comprised 345 SNPs (Fig. 1) which, at an LOD score of 4 , gave nine linkage groups (LG) representing the nine chromosomes of lettuce. These had a total length of $1,312 \mathrm{cM}$, with an individual length of 105-174 cM per LG. Each LG had 33-48 markers, with a median distance between the markers of $1.2-3.2 \mathrm{cM}$, except for LG9 that had 19 markers with a median distance between the markers of $4.2 \mathrm{cM}$.

Based on the 331 co-dominantly scored SNPs in $187 \mathrm{~F}_{2}$ plants, the whole crop genome was represented in the $\mathrm{F}_{2}$ population. The average crop allele content in the $\mathrm{F}_{2}$ plants was $50 \%$ as expected, with individuals comprising 28 $66 \%$ of crop alleles. The selection of the $98 \mathrm{~F}_{2}$ plants for the experiment did not alter the average crop genome content. Using a significance level of 0.05 corrected for multiple tests by the Bonferroni method $(\alpha=0.05 / 331$, Bland and Altman 1995), eight markers (2.4\%) had crop/wild allele frequency ratios that significantly deviated from the expected $1: 1$ ratio ( $\chi^{2}$ ranging from 14 to 65 ). Three of these markers could not be placed on the map and the remaining five mapped on LG3 where they spanned a continuous segment of $76 \mathrm{cM}$, with a bias towards the crop allele (Fig. 1). The flanking markers had relatively high $\chi^{2}$ values as well $\left(P_{\chi^{2}}=0.0015\right)$ on both sides of the segment, indicating a non-random effect of segregation distortion of the segment. 
Table 1 Mean, range values and heritability for measured traits of the $\mathrm{F}_{2: 3}$ families and their parents under drought, salinity, nutrient deficiency and non-stress conditions

\begin{tabular}{|c|c|c|c|c|c|c|c|}
\hline \multirow[t]{2}{*}{ Trait } & \multirow[t]{2}{*}{ Treatment } & \multirow[t]{2}{*}{ L. serriola mean } & \multirow[t]{2}{*}{ L. sativa mean } & \multicolumn{4}{|c|}{$\mathrm{F}_{2: 3}$ families } \\
\hline & & & & Mean & Min & $\operatorname{Max}$ & $H^{2}$ \\
\hline \multirow[t]{5}{*}{ Plant height $(\mathrm{cm})$} & Control-D & 35.88 & 25.69 & 32.95 & 26.49 & 44.99 & 0.84 \\
\hline & Drought & 21.63 & 17.85 & 20.52 & 16.80 & 26.43 & 0.82 \\
\hline & Control-SN & 57.68 & 22.85 & 43.31 & 13.17 & 89.28 & 0.98 \\
\hline & Salt & 27.08 & 14.72 & 25.68 & 13.34 & 53.53 & 0.99 \\
\hline & Nutrient deficiency & 21.22 & 12.12 & 18.91 & 10.03 & 48.07 & 0.98 \\
\hline \multirow[t]{5}{*}{ Fresh weight (g) } & Control-D & 44.76 & 72.55 & 53.14 & 31.91 & 69.55 & 0.90 \\
\hline & Drought & 10.22 & 13.94 & 11.16 & 8.46 & 14.02 & 0.51 \\
\hline & Control-SN & 34.51 & 55.18 & 42.25 & 28.5 & 53.44 & 0.86 \\
\hline & Salt & 12.64 & 24.98 & 15.28 & 9.38 & 19.92 & 0.83 \\
\hline & Nutrient deficiency & 7.46 & 10.73 & 8.10 & 5.62 & 10.53 & 0.66 \\
\hline \multirow[t]{5}{*}{ Dry weight (g) } & Control-D & $3.08^{\mathrm{a}}$ & 3.20 & 3.02 & 1.60 & 4.39 & 0.90 \\
\hline & Drought & $1.83^{\mathrm{a}}$ & 1.91 & 1.62 & 1.19 & 1.96 & 0.66 \\
\hline & Control-NS & $2.98^{\mathrm{a}}$ & 2.46 & 2.91 & 2.12 & 4.32 & 0.90 \\
\hline & Salt & 1.33 & 1.97 & 1.54 & 1.09 & 2.21 & 0.80 \\
\hline & Nutrient deficiency & 1.05 & 1.58 & 1.14 & 0.78 & 1.58 & 0.71 \\
\hline Relative moisture & Control-D & 93.09 & 95.62 & 94.44 & 93.07 & 95.73 & 0.82 \\
\hline \multirow[t]{4}{*}{ Content $(\%)$} & Drought & 81.47 & 85.49 & 84.67 & 79.38 & 88.50 & 0.89 \\
\hline & Control-SN & 91.31 & 95.56 & 93.08 & 88.62 & 94.57 & 0.93 \\
\hline & Salt & 89.41 & 92.10 & 89.84 & 85.99 & 91.78 & 0.96 \\
\hline & Nutrient deficiency & $85.88^{\mathrm{a}}$ & 85.32 & 85.81 & 81.53 & 88.76 & 0.89 \\
\hline \multirow[t]{2}{*}{$\mathrm{Na}^{+}(\mu \mathrm{g} / \mathrm{g}$ dry weight $)$} & Control-SN & 11.02 & 13.24 & 9.19 & 3.18 & 20.70 & - \\
\hline & Salt & 24.35 & 49.91 & 31.47 & 8.32 & 54.89 & - \\
\hline \multirow[t]{2}{*}{$\mathrm{Cl}^{-}$( $\mu \mathrm{g} / \mathrm{g}$ dry weight $)$} & Control-SN & 10.51 & 19.28 & 15.56 & 7.24 & 22.13 & - \\
\hline & Salt & 56.37 & 78.47 & 67.78 & 20.65 & 105.67 & - \\
\hline \multirow[t]{2}{*}{$\mathrm{K}^{+}(\mu \mathrm{g} / \mathrm{g}$ dry weight $)$} & Control-SN & 44.14 & 82.77 & 66.14 & 38.36 & 93.07 & - \\
\hline & Salt & 49.91 & 39.22 & 49.10 & 23.39 & 72.92 & - \\
\hline
\end{tabular}

Control-D control treatment in the drought experiment; control-SN control treatment in the salt-nutrient deficiency experiment

${ }^{a}$ L. serriola and $L$. sativa not significantly different

QTL analysis

Seventeen QTLs were mapped for vigour traits (plant height, fresh weight, dry weight and relative moisture content) and six QTLs were mapped for ion content traits $\left(\mathrm{Na}^{+}, \mathrm{Cl}^{-}\right.$and $\left.\mathrm{K}^{+}\right)$. The details about the detected QTLs under control and stress conditions are shown in Table 3 and their locations on the linkage map are presented in Fig. 1. The QTLs were located on eight linkage groups, with LG1 having no QTL. The dominance effects of the QTLs were not significant, except for two QTLs, one for fresh weight and another one for $\mathrm{Na}^{+}$content, indicating that the vigour of the hybrids was not mainly due to the heterozygous genotypes. QTL by environment interaction (here, the environments represented by the treatments) was significant for all the vigour trait QTLs and $\mathrm{Cl}^{-}$content QTLs. This non-additive QTL effect from one treatment to another was due to the presence of a QTL in one treatment and its absence in another or to a differential QTL allelic effect characterized by unequal or opposite allelic effect from one treatment to another.

Eleven QTLs were detected in the drought experiment and seven of them had a positive effect from the crop allele. Five of the QTLs were common in the control and drought treatments, while three were specific to the control treatment and three were specific to the drought treatment. Fifteen vigour QTLs were detected in the salt-nutrient experiment with five of them having a positive effect from the crop allele and three QTLs having a positive effect from the crop allele in either the control or salt treatment and a positive effect from the wild allele in the nutrient-deficiency treatment. Plant height was solely inherited from the wild parent in all the treatments, while the other vigour traits were inherited from both the crop and the wild parents.

Although the QTLs were located on eight out of nine lettuce LGs, 16 of the 23 detected QTLs were located on 
Table 2 Pearson's coefficients of correlation among the traits

\begin{tabular}{|c|c|c|c|c|c|c|c|}
\hline Trait & Treatment & Plant height & Fresh weight & Dry weight & Relative moisture content & $\mathrm{Na}^{+}$ & $\mathrm{Cl}^{-}$ \\
\hline \multirow[t]{5}{*}{ Fresh weight } & Control-D & 0.28 & & & & & \\
\hline & Drought & 0.50 & & & & & \\
\hline & Control-SN & $0.04^{\mathrm{ns}}$ & & & & & \\
\hline & Nutrient deficiency & 0.40 & & & & & \\
\hline & Salt & -0.18 & & & & & \\
\hline \multirow[t]{5}{*}{ Dry weight } & Control-D & 0.35 & 0.83 & & & & \\
\hline & Drought & 0.29 & 0.58 & & & & \\
\hline & Control-SN & 0.59 & 0.61 & & & & \\
\hline & Nutrient deficiency & 0.24 & 0.76 & & & & \\
\hline & Salt & 0.33 & 0.77 & & & & \\
\hline \multirow[t]{5}{*}{ Relative moisture content } & Control-D & -0.24 & -0.19 & -0.69 & & & \\
\hline & Drought & 0.31 & 0.64 & -0.17 & & & \\
\hline & Control-SN & -0.68 & 0.13 & -0.65 & & & \\
\hline & Nutrient deficiency & 0.17 & 0.12 & -0.52 & & & \\
\hline & Salt & -0.80 & 0.17 & -0.47 & & & \\
\hline $\mathrm{Na}^{+}$ & Salt & -0.56 & 0.56 & $0.03^{\mathrm{ns}}$ & 0.69 & & \\
\hline $\mathrm{Cl}^{-}$ & Salt & -0.77 & 0.65 & $0.07^{\mathrm{ns}}$ & 0.80 & 0.79 & \\
\hline $\mathrm{K}^{+}$ & Salt & -0.32 & $0.01^{\mathrm{ns}}$ & $-0.13^{\mathrm{ns}}$ & 0.23 & -0.31 & 0.20 \\
\hline
\end{tabular}

Control-D control treatment in the drought experiment; control-NS control treatment in the salt-nutrient deficiency experiment; $n s$ correlation coefficient not significant $(P>0.05)$

three LGs. These were LG4, 7 and 9 and they constituted QTL "hotspots" because the QTLs overlapped on the same segments (Fig. 1). On LG7, six QTLs overlapped on a chromosome segment of $28 \mathrm{cM}$ and two more QTLs overlapped in a neighbouring region. Five QTLs overlapped on LG9 and three QTLs overlapped on LG4.

QTL epistatic effect

Twenty-one QTL pairs epistatically affected the traits under the five treatments, increasing the explained phenotypic variance by $6-12 \%$ (Table 4 ). Heterozygosity did not play an important role in the epistatic effect: for 18 QTL pairs, the predicted means for homozygous genotype combinations were equal to or greater than the predicted means for the heterozygous combinations. Four of these QTL pairs were homozygous for the crop allele, six were homozygous for the wild allele, and eight of the QTL pairs were homozygous for the crop allele at one locus and homozygous for the wild allele at the other locus.

\section{Discussion}

We studied the tolerance of young lettuce crop-wild hybrid plants to drought, salinity and nutrient deficiency and mapped 17 QTLs associated with plant vigour under those conditions in $\mathrm{F}_{2: 3}$ families derived from a cross between
L. serriola and L. sativa. In Avena barbata, early plant growth was found positively correlated to survival, fully grown plant biomass and plant fitness under field conditions (Latta and McCain 2009). In lettuce crop-wild hybrids, selection mainly takes place on young plants, leading to surviving lineages with higher vigour and fitness than the wild genotypes (Hooftman et al. 2005, 2009). Nevertheless, our results can only be taken as a first approach to assessing fitness in wild populations, as this would call for following complete growth cycles from seed to seed. We will discuss the effects of segregation distortion and QTLs affecting vigour on crop-wild introgression, and end with the possible implications for transgene dispersal mitigation.

\section{Segregation distortion}

Interspecific crosses have been reported to result in high pre-zygotic segregation distortion in progeny (ranging from 22 to $90 \%$ of the markers) and to be associated with reproduction barriers (Jenni and Hayes 2009; Yue et al. 2009; Platt et al. 2010). The relatively low rate of distorted segregation in the $\mathrm{F}_{2}$ population $(2.4 \%)$ is consistent with the close relatedness of $L$. serriola and $L$. sativa and the complete fertility between the two species (Ryder and Whitaker 1976; De Vries 1990; Kesseli et al. 1991; Koopman et al. 1998). In the same crop-wild cross, Hooftman et al. (2011) observed a segregation distortion of $7.5 \%$ 
1-F2

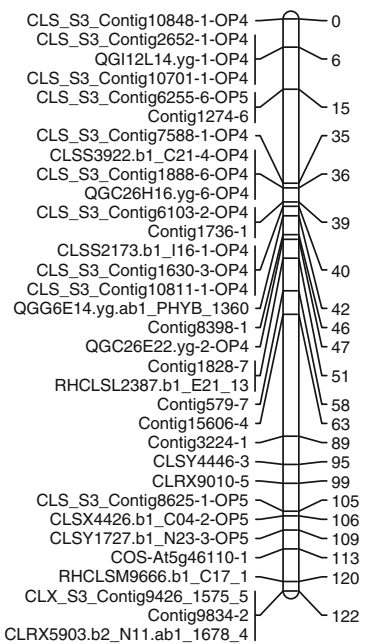

4-F2



Fig. 1 Linkage map of $345 \mathrm{SNPs}$ based on $187 \mathrm{~F}_{2}$ plants derived from a cross between $L$. sativa and $L$. serriola. The names of the markers are shown on the left of the LG bar and the distance is given on the right in centimorgans. The markers with distorted segregation are shown in red (distortion towards the crop allele). The genomic localizations of the QTLs for plant height (L), fresh weight $(\mathrm{FW})$, dry weight (DW), relative moisture content (RMC), sodium (Na),

under greenhouse (no mortality) conditions. Their results are similar to ours with the differences in percentage accountable to different methods of correcting the
3-F2

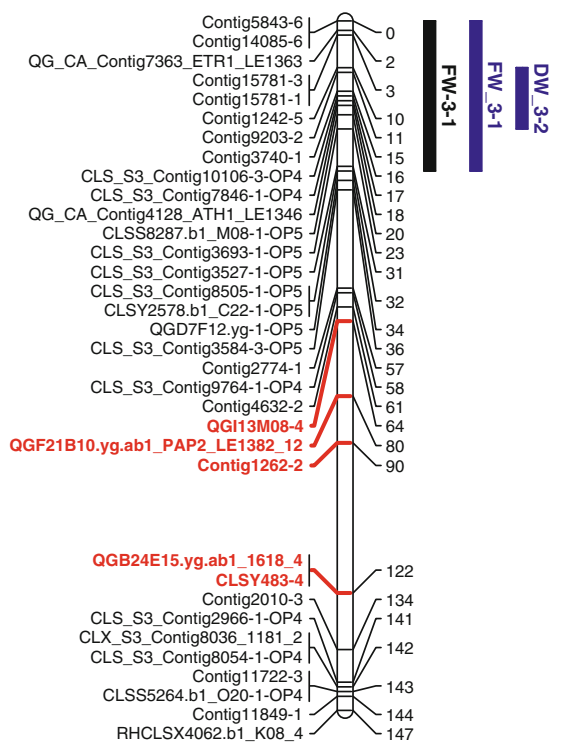

5-F2

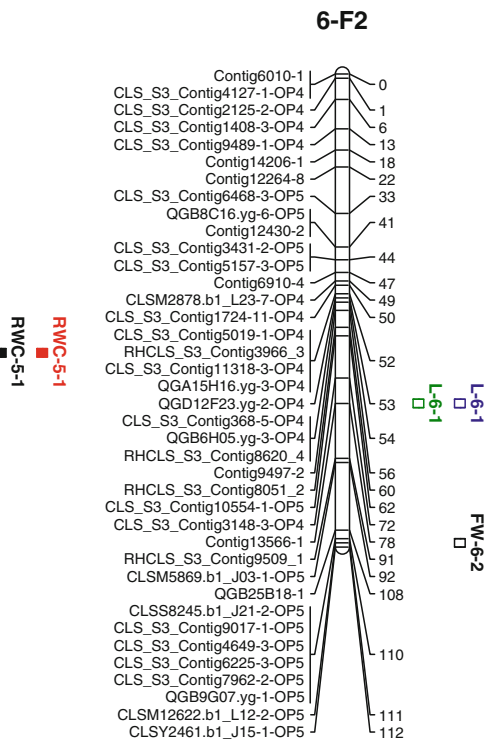

CLSS4558. Contig1356-2

CLSS4062.b1_K08-3-OP4

CLS_S3_Contig5165-1-OP4

Contig15257-1
Contig12280-1
CLS_S3_Contig2918-1-OP4
Contig13459-1
CLS_S3_Contig5326-1-OP4
CLS_S3_Contig4855-5-OP4

CLS_S3_Contig10599-6-OP4

RHCLS_S3_Contig7384_1 20

potassium $(\mathrm{K})$ and chloride $(\mathrm{Cl})$ as mapped under control (black), drought (red), salt (blue) and nutrient deficiency (green) conditions in $98 \mathrm{~F}_{2: 3}$ families are represented by the blocks. Solid QTL block: effect positive for the crop allele; open QTL block: effect positive for the wild allele. Map and QTLs displayed using MapChart 2.2 (Voorrips 2002)

significance level for multiple tests. The region on LG3 where the distortion was located in our study could unfortunately not be compared with the results of 
7-F2

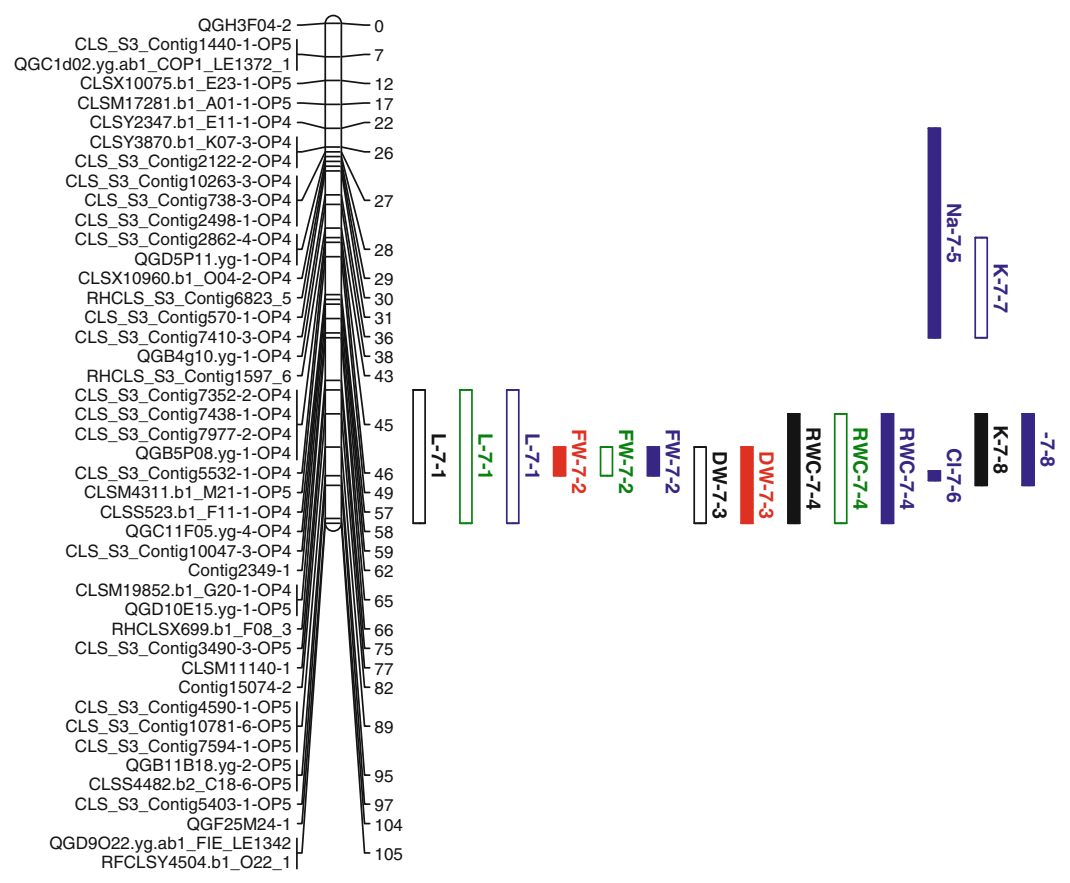

9-F2
8-F2

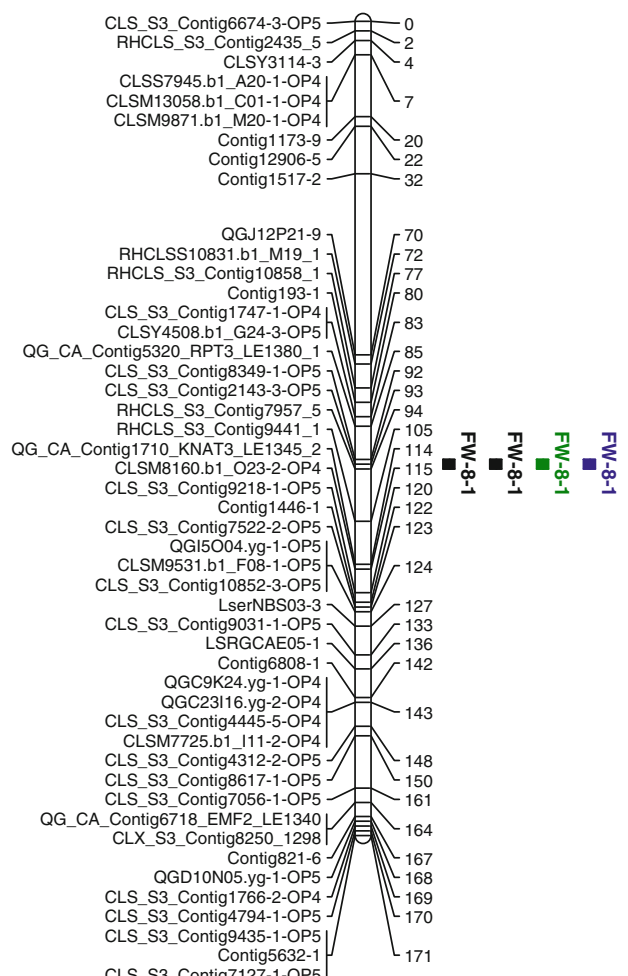

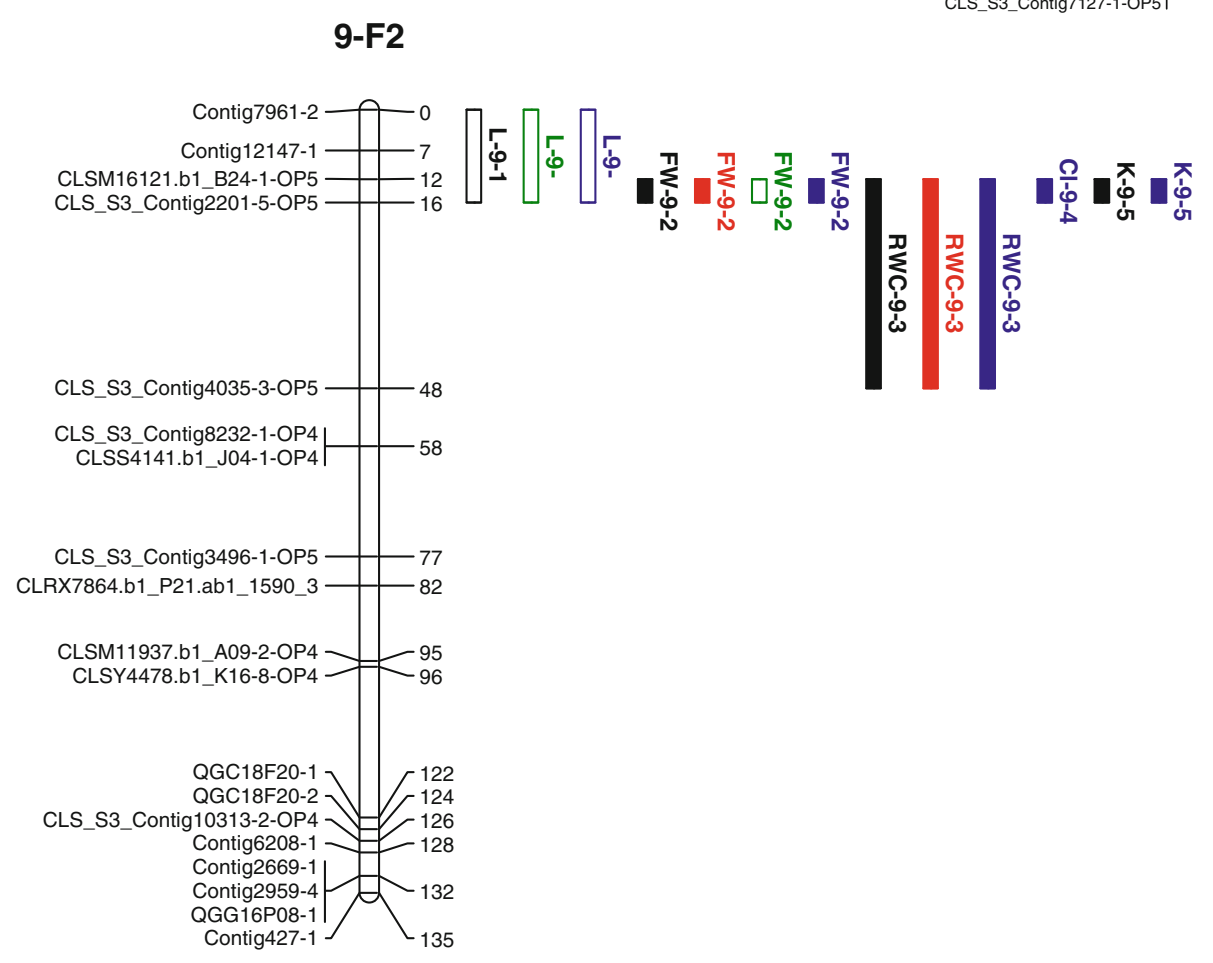

Fig. 1 continued

Hooftman et al. (2011) due to the lack of common markers. The occurrence of genomic regions at which one of the parental alleles is favoured during segregation may result in an increase in frequency of one parental allele at the expense of the other allele in subsequent generations. On one hand, further selfing of the hybrids will lead to a rapid fixation of the crop alleles in regions such as on LG3 where segregation is skewed in favour of the crop alleles, 


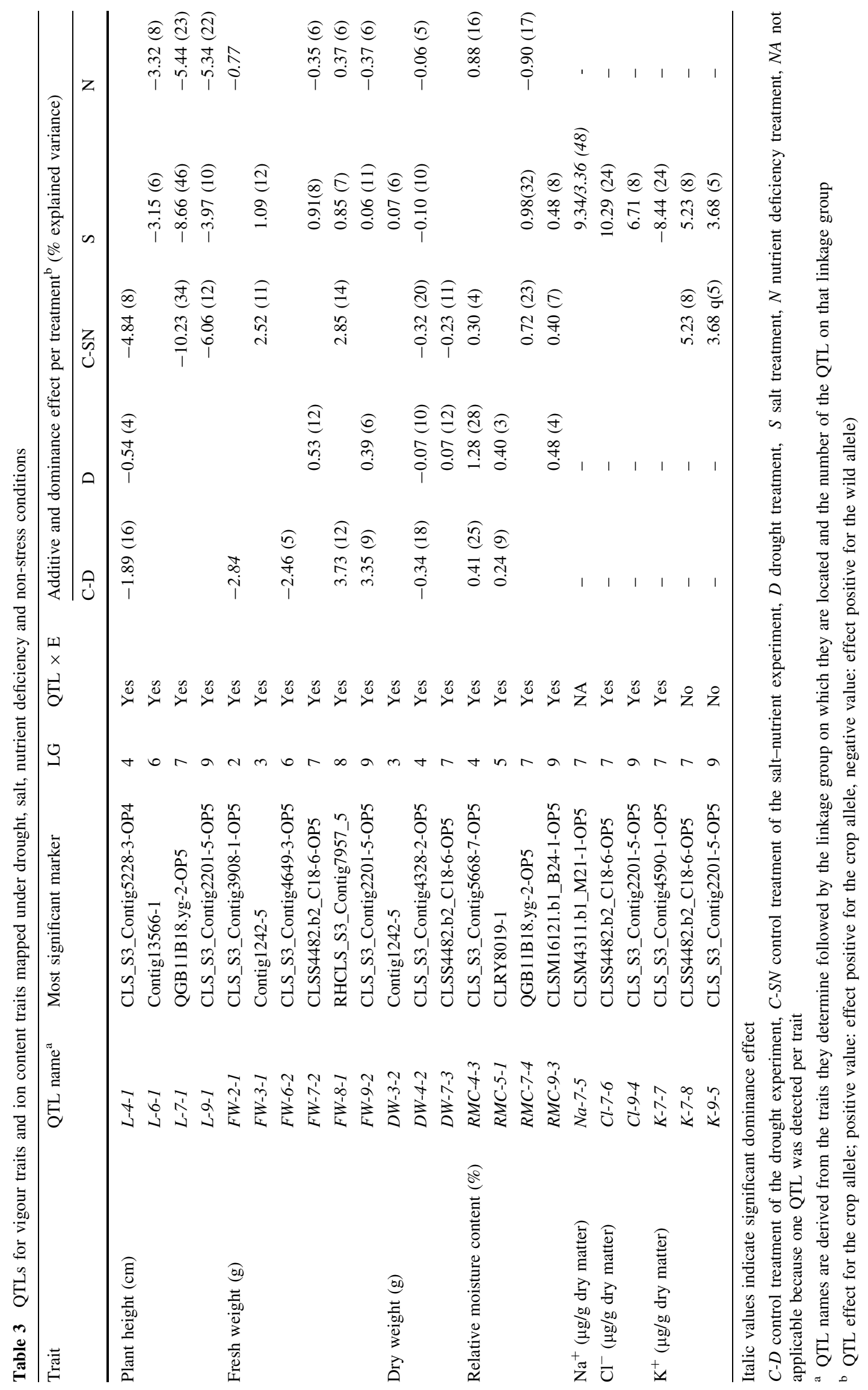


Table 4 Significant QTL $\times$ QTL interactions as detected by generalized linear model analysis fitting the main QTL effects and adding interaction between one pair of QTLs at a time

\begin{tabular}{|c|c|c|c|c|c|c|c|c|c|c|c|c|}
\hline \multirow[t]{2}{*}{ Treatment $^{\mathrm{a}}$} & \multirow[t]{2}{*}{ Trait } & \multirow[t]{2}{*}{$\mathrm{QTL} \times \mathrm{QTL}$} & \multirow{2}{*}{$\begin{array}{l}\% \text { expl. } \\
\text { variance }\end{array}$} & \multicolumn{9}{|c|}{ Predicted genotypic means ${ }^{\mathrm{b}}$} \\
\hline & & & & $\mathrm{a} / \mathrm{a}$ & $\mathrm{a} / \mathrm{h}$ & $\mathrm{a} / \mathrm{b}$ & $\mathrm{h} / \mathrm{a}$ & $\mathrm{h} / \mathrm{h}$ & $\mathrm{h} / \mathrm{b}$ & $\mathrm{b} / \mathrm{a}$ & $\mathrm{b} / \mathrm{h}$ & $\mathrm{b} / \mathrm{b}$ \\
\hline \multirow[t]{4}{*}{ C-D } & Plant height $(\mathrm{cm})$ & $L-6-1 \times R M C-5-1$ & 11 & 32.7 & 31.8 & 35.5 & 30.1 & 33.4 & 34.5 & 34.0 & 32.6 & 31 \\
\hline & Dry weight (g) & $F W-6-2 \times D W-4-2$ & 8 & 2.9 & 2.7 & 2.6 & 2.5 & 3.2 & 3.1 & 2.5 & 3.2 & 3. \\
\hline & \multirow{2}{*}{$\begin{array}{l}\text { Relative moisture } \\
\text { content }(\%)\end{array}$} & $L-4-1 \times R M C-5-1$ & 7 & 94.8 & 94.7 & 93.5 & 94.6 & 94.4 & 94.2 & 94.7 & 94.5 & 94 \\
\hline & & $F W-2-1 \times R M C-5-1$ & 7 & 94.7 & 94.9 & 94.0 & 94.8 & 94.3 & 94.1 & 94.5 & 94.6 & 94 \\
\hline \multirow[t]{3}{*}{ D } & Plant height $(\mathrm{cm})$ & $F W-8-1 \times D W-4-2$ & 12 & 18.2 & 21.3 & 20.4 & 19.7 & 20.8 & 20.2 & 20.7 & 19.4 & 2 \\
\hline & Dry weight (g) & $F W-3-1 \times R M C-4-3$ & 12 & 1.7 & 1.6 & 1.6 & 1.5 & 1.7 & 1.8 & 1.5 & 1.6 & \\
\hline & $\begin{array}{l}\text { Relative moisture } \\
\text { content }(\%)\end{array}$ & $L-6-1 \times F W-8-1$ & 9 & 85.3 & 84.0 & 84.2 & 83.9 & 85.1 & 86.3 & 83.7 & 84.3 & 85 \\
\hline \multirow[t]{9}{*}{ C-SN } & \multirow[t]{2}{*}{ Fresh weight (g) } & $L-4-1 \times L-9-1$ & 11 & 43.2 & 41.6 & 47.18 & 44.4 & 43.1 & 38.8 & 39.51 & 42.5 & 38.1 \\
\hline & & $L-6-1 \times R M C-4-3$ & 11 & 45.7 & 41.0 & 42.9 & 35.8 & 43.1 & 43.5 & 39.2 & 42.1 & 42.0 \\
\hline & \multirow[t]{4}{*}{ Dry weight (g) } & $L-4-1 \times L-9-1$ & 9 & 2.9 & 2.8 & 3.2 & 2.8 & 3.1 & 2.8 & 2.4 & 3.0 & 5. \\
\hline & & $L-4-1 \times L-7-1$ & 8 & 2.8 & 2.9 & 3.4 & 2.7 & 2.9 & 3.2 & 1.9 & 3.0 & 2.8 \\
\hline & & $L-7-1 \times L-9-1$ & 11 & 2.7 & 2.6 & 2.4 & 2.7 & 3.1 & 3.0 & 2.7 & 3.2 & 3.6 \\
\hline & & $L-7-1 \times F W-8-1$ & 7 & 2.6 & 2.6 & 3.1 & 3.2 & 2.9 & 2.7 & 3.6 & 3.2 & 2.8 \\
\hline & \multirow{3}{*}{$\begin{array}{l}\text { Relative moisture } \\
\text { content }(\%)\end{array}$} & $L-4-1 \times L-9-1$ & 6 & 93.4 & 93.2 & 93.1 & 93.6 & 92.83 & 92.8 & 94.0 & 92.9 & 91.9 \\
\hline & & $L-9-1 \times D W-4-2$ & 6 & 93.2 & 93.6 & 93.7 & 93.3 & 93.0 & 92.7 & 93.3 & 92.9 & 91.6 \\
\hline & & $D W-4-2 \times R M C-5-1$ & 6 & 94.0 & 93.7 & 92.4 & 93.4 & 93.2 & 93.1 & 92.0 & 92.4 & 92.9 \\
\hline \multirow[t]{2}{*}{$\mathrm{N}$} & Plant height $(\mathrm{cm})$ & $L-7-1 \times L-9-1$ & 6 & 11.2 & 7.7 & 14.0 & 13.1 & 20.0 & 25.4 & 15.6 & 25.7 & 31.6 \\
\hline & Dry weight (g) & $L-7-1 \times L-9-1$ & 12 & 1.3 & 1.2 & 1.1 & 1.1 & 1.2 & 1.2 & 1.0 & 1.1 & 1 . \\
\hline \multirow[t]{3}{*}{$\mathrm{S}$} & Plant height $(\mathrm{cm})$ & $L-4-1 \times L-9-1$ & 6 & 22.9 & 22.4 & 27.0 & 20.7 & 24.9 & 24.9 & 25.5 & 29.2 & 40.8 \\
\hline & Fresh weight (g) & $F W-6-2 \times R M C-5-1$ & 7 & 15.4 & 15.5 & 14.6 & 16.2 & 15.5 & 14.4 & 14.5 & 14.7 & 16. \\
\hline & $\begin{array}{l}\text { Relative moisture } \\
\text { content }(\%)\end{array}$ & $L-9-1 \times D W-4-2$ & 6 & 90.6 & 90.1 & 90.9 & 89.7 & 89.5 & 90.7 & 89.3 & 89.5 & 88.7 \\
\hline
\end{tabular}

${ }^{a} a$ homozygous for the crop allele, $b$ homozygous for the wild allele, $h$ heterozygous

b $C$ - $D$ control treatment of the drought experiment, $D$ drought, $C$-SN control treatment of the salt-nutrient experiment, $N$, nutrient, $S$ salt

regardless of the fitness effect of the crop (trans)genes. On the other hand, regions with segregation skewed in favour of the wild alleles will slow down the crop allele fixation, although none was identified in this specific cross. The identification of such genomic regions with pre- and postzygotic segregation distortion could be exploited to minimize the introgression likelihood of transgenes. However, those regions are relatively rare in the lettuce crop-wild crosses and the usefulness of such regions in minimizing the escape of transgenes will depend on the stability of the distortion over generations and across genotypes.

\section{Hybrid performance and QTL effects}

Hybridization between cultivated and wild lettuce resulted in a moderate to high heritability for the vigour traits and many of the hybrids showed improved vigour over the wild parent under non-stress and stress conditions. The results suggest that, if early vigour results in better fitness, lettuce hybrids could outperform the wild parent under stress conditions of salinity, drought and nutrient deficiency.
These results also are in line with previous experiments on lettuce, which have shown that crop-wild hybrids could perform equally or better than the wild parent and that, depending on their fitness, hybrids could displace the wild taxon L. serriola in its natural habitat (Hooftman et al. 2005, 2008). In addition, transgressive segregation was observed among the progeny of our lettuce cross, as also found in a cross of $A$. barbata ecotypes varying in drought tolerance by Latta et al. (2010). Despite the close relatedness between $L$. serriola and $L$. sativa and $L$. sativa's most likely domestication from ancient population(s) of L. serriola, a recent large-scale population genetic study on crop-wild gene flow using microsatellite data on a large genebank collection and samples of wild $L$. serriola from all over Europe has shown that the two species are still for the largest part genetically distinguishable (Uwimana et al. 2012a). Improved hybrid vigour in early generations of hybrids may be associated with heterosis, which in turn could be based on dominance, overdominance and/or epistatic loci in the repulsion phase (pseudo-overdominance) (Birchler et al. 2003; Burke and Arnold 2001). 
Combination of epistatic and additive allelic effects from two parents at different loci in the repulsion phase has been associated with the origin of transgressive segregation that leads to the creation of superior phenotypes (Latta et al. 2010). It has been considered that this could even lead to ecologically diverging phenotypes that could invade new ecological areas, such as the sunflower hybrid species Helianthus paradoxus (Lexer et al. 2003a, b) and cropwild hybrid radish (Raphanus spp.) (Campbell et al. 2006; Campbell and Snow 2007).

Hybrid vigour due to dominance and overdominance is expected to be short lived, as it is associated with the advantage of the heterozygote genotypes, which breaks down over subsequent generations due to selfing. In this study, additivity was the major allelic action at 16 of the 17 vigour QTLs identified in the $\mathrm{F}_{2}$ population. Dominance was significant for one vigour QTL $(F W-2-1)$. This suggests that dominance is not the most important genetic basis behind the improved vigour among $\mathrm{F}_{2: 3}$ families. Conversely, epistasis as a result of non-additive effect of genotypes at two QTLs was significant for the traits under stress and control conditions. Despite the proven importance of epistasis on polygenic traits (Yu et al. 1998; Tisné et al. 2010), it is often underestimated due to the required large population size, which is experimentally challenging to handle, combined with computational load, which makes it difficult to scan all pairs of loci, especially in highly heterozygous populations such as an $F_{2}$ (Carlborg and Haley 2004). In a whole genome epistasis analysis, Bai et al. (2010) found that the interaction between identified QTLs accounted only for $18 \%$ of all the interacting pairs of loci. We have probably also underestimated epistasis, as it was calculated only for those loci whose main effect was significant on their own and background loci were not included in the interaction analysis. Despite including only a subset of all loci in the analysis, the effect of epistasis was significant and it accounted for $6-12 \%$ of the phenotypic variance of the traits per pair.

\section{QTL effects and transgene dispersal mitigation}

QTLs affecting vigour negatively could be used to reduce transgene dispersal when they would be in close linkage to the transgene (Kwit et al. 2011). For a GM approach to such containment, i.e. linking the transgene for the desired trait to a gene conferring a disadvantage under natural growing conditions, such as a dwarfing gene, proofs of principle have been reported for tobacco under greenhouse conditions (Al-Ahmad et al. 2004) and for oilseed rape in the field (Rose et al. 2009). In the present study, we have been searching for genomic regions with such a gene. Many of the vigour QTLs in our stress experiments mapped to the same genomic regions, notably on LG4, LG7 and LG9. The QTL region on LG7 corresponds to the QTL for germination under low and high temperature with a positive effect from the wild allele found in the crop-wild cross Salinas $\times L$. serriola UC96US23 (Argyris et al. 2005). It also overlaps with the QTL for the number of lateral roots in the bottom length of the taproot with a positive effect from the wild allele in the same cross (Johnson et al. 2000). Co-localizing QTLs were also obtained by Baack et al. (2008) for traits related to survival and morphology in a recombinant inbred line population of crop-wild sunflower hybrids. QTL co-localization may be due to a pleiotropic effect, if one QTL affects more than one trait, but it is also possible that the QTLs are genetically linked and inseparable with the markers and recombination events observed in this study. The combination of QTL hotspots with QTL $\times$ treatment interaction through opposite allelic effect across treatments makes it difficult to choose which QTL region favours which parental allele. Nevertheless, these regions will remain under selection, positively or negatively, depending on to the prevailing conditions (optimum, dry, saline or nutrient deficient). Therefore, as insertion site of a transgene, such QTL regions could better be avoided because there is always a chance that the regions happen to come under positive selection, leading to an increased frequency of linked loci through genetic hitchhiking, and thus to a higher likelihood of introgression of crop alleles or transgenes into the wild population (Stewart et al. 2003; Hooftman et al. 2011; Kwit et al. 2011). As a consequence of the "hotspots" of vigour QTLs, examples of QTLs with apparently more simple implications for transgene presence were relatively few, e.g. on LG2 where only wild alleles were favoured and LG8 where only crop alleles were favoured. The LG8 QTL could thus clearly be better avoided, whereas the LG2 QTL could be hypothesized to be a safer place, but as there were only two conditions with the wild allele effect, this has only weak support (see Fig. 1). From $F_{1}$ progeny, the natural process of introgression in lettuce will continue with the creation of inbred lines through continued selfing or backcrosses to L. serriola, or a combination of the two. In an accompanying study, QTLs were also assessed in $\mathrm{BC}_{1}$ and $\mathrm{BC}_{2}$, where similar QTL "hotspots" were found as in the $F_{2}$ (Uwimana et al. 2012b). With regard to the above examples, the LG8 QTL with positive crop allele effects were confirmed, but the LG2 QTL was not found.

This study was limited to a single cross and to measuring plant vigour at an early stage of growth of the hybrid plants under controlled greenhouse conditions, while spontaneous crop-wild hybrids grow under natural field conditions. Additionally, greenhouse and field experiments are not always consistent (Gardner and Latta 2008; Latta and McCain 2009). Hence, in follow-up experiments hybrids from another cross are evaluated as well, and the 
hybrids are evaluated on the field in order to correlate early vigour with adulthood and reproduction, and link individual stress treatment with field conditions, which may encompass multiple abiotic stress factors in combination with biotic stress factors such as diseases and herbivores.

Acknowledgments This study was financially supported by The Netherlands Organization for Scientific Research (NWO) through their research programme "Ecology Regarding Genetically modified Organisms" (ERGO project 838.06.041). The contributions of Leah K. McHale and Richard W. Michelmore were supported by the National Science Foundation Plant Genome Program Grant \#: DBI0421630.

Open Access This article is distributed under the terms of the Creative Commons Attribution License which permits any use, distribution, and reproduction in any medium, provided the original author(s) and the source are credited.

\section{References}

Abdeen A, Schnell J, Miki B (2010) Transcriptome analysis reveals absence of unintended effects in drought-tolerant transgenic plants overexpressing the transcription factor $A B F 3$. BMC Genomics 11:69

Al-Ahmad H, Galili S, Gressel J (2004) Tandem constructs to mitigate transgene persistence: tobacco as a model. Mol Ecol 13: 697-710

Albacete AA, Martínez-Andújar C, Pascual JA, Acosta M, PérezAlfocea F (2008) Increasing vegetative growth, yield and seed quantity in tomato by inducing plant vigour at the earliest seedling stage. Acta Hort 782:265-271

Argyris J, Truco MJ, Ochoa O, Knapp SJ, Still DW, Lenssen GM, Schut JW, Michelmore RW, Bradford KJ (2005) Quantitative trait loci associated with seed and seedling traits in Lactuca. Theor Appl Genet 111:1365-1376

Arias DM, Rieseberg LH (1994) Gene flow between cultivated and wild sunflowers. Theor Appl Genet 89:655-660

Baack EJ, Sapir Y, Chapman MA, Burke JM, Rieseberg LH (2008) Selection on domestication traits and quantitative trait loci in crop-wild sunflower hybrids. Mol Ecol 17:666-677

Bai W, Zhang H, Zhang Z, Teng F, Wang L, Tao Y, Zheng Y (2010) The evidence for non-additive effect as the main genetic component of plant height and ear height in maize using introgression line populations. Plant Breed 129:376-384

Birchler JA, Auger DL, Riddle NC (2003) In search of the molecular basis of heterosis. Plant Cell 15:2236-2239

Bland JM, Altman DG (1995) Multiple significance tests: the Bonferroni method. Br Med J 310:170

Burke JM, Arnold ML (2001) Genetics and the fitness of hybrids. Annu Rev Genet 35:31-52

Campbell LG, Snow AA (2007) Competition alters life history and increases the relative fecundity of crop-wild radish hybrids (Raphanus spp.). New Phytol 173:648-660

Campbell LG, Snow AA, Ridley CE (2006) Weed evolution after crop gene introgression: greater survival and fecundity of hybrids in a new environment. Ecology Lett 9:1198-1209

Carlborg Ö, Haley CS (2004) Epistasis: too often neglected in complex trait studies? Nat Rev Genet 5:618-625

Castiglioni P, Warner D, Bensen RJ, Anstrom DC, Harrison J, Stoecker M, Abad M, Kumar G, Salvador S, D’Ordine R, Navarro S, Back S,
Fernandes M, Targolli J, Dasgupta S, Bonin C, Luethy MH, Heard JE (2008) Bacterial RNA chaperones confer abiotic stress tolerance in plants and improved grain yield in maize under water-limited conditions. Plant Physiol 147:446-455

Chahal GS, Gosal SS (2002) Principles and procedures of plant breeding: Biotechnological and conventional approaches. Alpha Science International Ltd, Harrow

Choi J, Seo Y, Kim S, Kim W, Shin J (2011) Constitutive expression of CaXTH3, a hot pepper xyloglucan endotransglucosylase/ hydrolase, enhanced tolerance to salt and drought stresses without phenotypic defects in tomato plants (Solanum lycopersicum cv. Dotaerang). Plant Cell Rep 30:867-877

D'Andrea L, Felber F, Guadagnuolo R (2008) Hybridization rates between lettuce (Lactuca sativa) and its wild relative (L. serriola) under field conditions. Environ Biosaf Res 7:61-71

De Vries IM (1990) Crossing experiments of lettuce cultivars and species (Lactuca sect. Lactuca, Compositae). Plant Syst Evol 171:233-248

Donohue K, Rubio de Casas R, Burghardt L, Kovach K, Willis CG (2010) Germination, postgermination adaptation, and species ecological ranges. Annu Rev Ecol Evol Syst 41:293-319

Foolad MR (1996) Genetic analysis of salt tolerance during vegetative growth in tomato, Lycopersicon esculentum Mill. Plant Breed 115:245-250

Gardner KM, Latta RG (2008) Heritable variation and genetic correlation of quantitative traits within and between ecotypes of Avena barbata. J Evol Biol 21:737-748

Giannino D, Nicolodi C, Testone G, Di Giacomo E, Iannelli MA, Frugis G, Mariotti D (2008) Pollen-mediated transgene flow in lettuce (Lactuca sativa L.). Plant Breed 127:308-314

Hails RS, Morley K (2005) Genes invading new populations: a risk assessment perspective. Trends Ecol Evol 20:245-252

Hall L, Topinka K, Huffman J, Davis L, Good A (2000) Pollen flow between herbicide-resistant Brassica napus is the cause of multiple-resistant B. napus volunteers. Weed Sci 48:688-694

Hill M, Witsenboer H, Zabeau M, Vos P, Kesseli R, Michelmore R (1996) PCR-based fingerprinting using AFLPs as a tool for studying genetic relationships in Lactuca spp. Theor Appl Genet 93:1202-1210

Hoc PS, Espert SM, Drewes SI, Burghardt AD (2006) Hybridization between wild and domesticated types of Phaseolus vulgaris $L$. (Fabaceae) in Argentina. Genet Resour Crop Evol 53:331-337

Holland JB (2007) Genetic architecture of complex traits in plants. Curr Opin Plant Biol 10:156-161

Hooftman DAP, Oostermeijer JGB, Jacobs MMJ, Den Nijs HCM (2005) Demographic vital rates determine the performance advantage of crop-wild hybrids in lettuce. J Appl Ecol 42:10861095

Hooftman DAP, De Jong MJ, Oostermeijer JGB, Den Nijs HCM (2007) Modelling the long-term consequences of crop-wild relative hybridization: a case study using four generations of hybrids. J Appl Ecol 44:1035-1045

Hooftman DAP, Oostermeijer JGB, Marquard E, Den Nijs HCM (2008) Modelling the consequences of crop-wild relative gene flow: a sensitivity analysis of the effects of outcrossing rates and hybrid vigour breakdown in Lactuca. J Appl Ecol 45:1094-1103

Hooftman DAP, Hartman Y, Oostermeijer JGB, Den Nijs HCM (2009) Existence of vigorous lineages of crop-wild hybrids in Lettuce under field conditions. Environ Biosaf Res 4:203-217

Hooftman DAP, Flavell AJ, Jansen H, Den Nijs HCM, Syed NH, Sørensen AP, Orozco-ter Wengel P, Van de Wiel CCM (2011) Locus-dependent selection in crop-wild hybrids of lettuce under field conditions and its implication for GM crop development. Evol Appl 4:648-659

Jansen J, van Hintum TJL (2007) Genetic distance sampling: a novel sampling method for obtaining core collections using genetic 
distances with an application to cultivated lettuce. Theor Appl Genet 114:421-428

Jansen J, De Jong AG, Van Ooijen JW (2001) Constructing dense genetic linkage maps. Theor Appl Genet 102:1113-1122

Jenni S, Hayes RJ (2009) Genetic variation, genotype $\times$ environment interaction, and selection for tipburn resistance in lettuce in multi-environments. Euphytica 171:427-439

Johnson WC, Jackson LE, Ochoa O, van Wijk R, Peleman J, St.Claire DA, Michelmore RW (2000) Lettuce, a shallow-rooted crop, and Lactuca serriola, its wild progenitor, differ at QTL determining root architecture and deep soil water exploitation. Theor Appl Genet 101:1066-1073

Kaufman L, Rousseeuw PJ (1990) Finding groups in data. An introduction to cluster analysis, Wiley

Kesseli RV, Ochoa O, Michelmore RW (1991) Variation at RFLP loci in Lactuca spp. and origin of cultivated lettuce ( $L$. sativa). Genome 34:430-436

Kiær LP, Felber F, Flavell A, Guadagnuolo R, Guiatti D, Hauser TP, Olivieri AM, Scotti I, Syed N, Vaschi M, Van de Wiel CCM, Jørgensen RB (2009) Spontaneous gene flow and population structure in wild and cultivated chicory, Cichorium intybus L. Genet Resour Crop Evol 56:405-419

Koopman WJM, Guetta E, Van De Wiel CCM, Vosman B, Van Den Berg RG (1998) Phylogenetic relationships among Lactuca (Asteraceae) species and related genera based on ITS-1 DNA sequences. Am J Bot 85:1517-1530

Kwit C, Moon HS, Warwick SI, Stewart CN (2011) Transgene introgression in crop relatives: molecular evidence and mitigation strategies. Trends Biotechnol 29:284-293

Latta RG, McCain C (2009) Path analysis of natural selection via survival and fecundity across contrasting environments in Avena barbata. J Evol Biol 22:2458-2469

Latta RG, Gardner KM, Staples DA (2010) Quantitative trait locus mapping of genes under selection across multiple years and sites in Avena barbata: epistasis, pleiotropy, and genotype-by-environment interactions. Genetics 185:375-385

Lebeda A, Doležalová I, Kř́śstková E, Mieslerová B (2001) Biodiversity and ecogeography of wild Lactuca spp. in some European countries. Genet Resour Crop Evol 48:153-164

Lee D, Natesan E (2006) Evaluating genetic containment strategies for transgenic plants. Trends Biotechnol 24:109-114

Lexer C, Welch ME, Durphy JL, Rieseberg LH (2003a) Natural selection for salt tolerance quantitative trait loci (QTLs) in wild sunflower hybrids: implications for the origin of Helianthus paradoxus, a diploid hybrid species. Mol Ecol 12:1225-1235

Lexer C, Welch ME, Raymond O, Rieseberg LH (2003b) The origin of ecological divergence in Helianthus paradoxus (Asteraceae): selection on transgressive characters in a novel hybrid habitat. Evolution 57:1989-2000

Li J, Ji L (2005) Adjusting multiple testing in multilocus analyses using the eigenvalues of a correlation matrix. Heredity 95:221227

Li B, Li N, Duan X, Wei A, Yang A, Zhang J (2010) Generation of marker-free transgenic maize with improved salt tolerance using the FLP/FRT recombination system. J Biotechnol 145:206-213

Lindqvist K (1960) Cytogenetic studies in the serriola group of Lactuca. Hereditas 46:75-151

Malosetti M, Voltas J, Romagosa I, Ullrich SE, van Eeuwijk FA (2004) Mixed models including environmental covariables for studying QTL by environment interaction. Euphytica 137:139_ 145

Mathews KL, Malosetti M, Chapman S, McIntyre L, Reynolds M, Shorter R, Van Eeuwijk F (2008) Multi-environment QTL mixed models for drought stress adaptation in wheat. Theor Appl Genet 117:1077-1091
McHale LK, Truco M, Kozik A, Wroblewski T, Ochoa OE, Lahre KA, Knapp SJ, Michelmore RW (2009) The genomic architecture of disease resistance in lettuce. Theor Appl Genet 118:565580

Nagata RT (1992) Clip-and-wash method of emasculation for lettuce. HortScience 27:907-908

Odong TL, van Heerwaarden J, Jansen J, van Hintum TJL, van Eeuwijk FA (2011) Statistical techniques for constructing reference sets of accessions and microsatellite markers. Crop Sci 51:2401-2411

Payne RW, Murray DA, Harding SA, Baird DB, Soutar DM (2011) An introduction to GenStat for Windows (14th Edition). VSN International, Hemel Hempstead

Platt A, Vilhjálmsson BJ, Nordborg M (2010) Conditions under which genome-wide association studies will be positively misleading. Genetics 186:1045-1052

Rieseberg LH, Baird SJE, Gardner KA (2000) Hybridization, introgression, and linkage evolution. Plant Mol Biol 42:205-224

Rose CW, Millwood RJ, Moon HS, Rao M, Halfhill M, Raynmer P, Warwick S, Al-Ahmad H, Gressel J, Stewart CN (2009) Genetic load and transgenic mitigating genes in transgenic Brassica rapa (field mustard) $\times$ Brassica napus (oilseed rape) hybrid populations. BMC Biotechnol 9:93

Ryder EJ (1999) Lettuce, Endive and Chicory. CAB International, Wallingford

Ryder EJ, Whitaker TW (1976) Lettuce. Lactuca sativa (Compositae). In: Simmonds NW (ed) Evolution of crop plants. Longman, London, pp 39-41

Snow AA, Pilson D, Rieseberg LH, Paulsen MJ, Pleskac N, Reagon MR, Wolf DE, Selbo SM (2003) A Bt transgene reduces herbivory and enhances fecundity in wild sunflowers. Ecol Appl 13:279-286

Snow AA, Andow DA, Gepts P, Hallerman EM, Power A, Tiedje JM, Wolfenbarger LL (2005) Genetically engineered organisms and the environment: current status and recommendations. Ecol Appl 15:377-404

Stewart CN, Halfhill MD, Warwick SI (2003) Transgene introgression from genetically modified crops to their wild relatives. Nature Rev Genet 4:806-817

Stolte S, Steudte S, Markowska A, Arning J, Neumann J, Stepnowski $P$ (2011) Ion chromatographic determination of structurally varied ionic liquid cations and anions: a reliable analytical methodology applicable to technical and natural matrices. Anal Meth 3:919-926

Thompson RC, Whitaker TW, Bohn GW, Van Horn CW (1958) Natural cross-pollination in lettuce. Am Soc Hort Sci 72:403409

Tiedje JM, Colwell RK, Grossman YL, Hodson RW, Lenski RE, Mack RN, Regal PJ (1989) The planned introduction of genetically engineered organisms: ecological considerations and recommendations. Ecology 70:298-315

Tisné S, Schmalenbach I, Reymond M, Dauzat M, Pervent M, Vile D, Granier C (2010) Keep on growing under drought: genetic and developmental bases of the response of rosette area using a recombinant inbred line population. Plant Cell Environ 33:18751887

Uwimana B, D'Andrea L, Felber F, Hooftman DAP, den Nijs HCM, Smulders MJM, Visser RGF, van de Wiel CCM (2012a) A Bayesian analysis of gene flow from crops to their wild relatives: cultivated (Lactuca sativa L.) and prickly lettuce (L. serriola L.), and the recent expansion of L. serriola in Europe. Mol Ecol 21: 2640-2654

Uwimana B, Smulders MJM, Hooftman DAP, Hartman Y, van Tienderen PH, Jansen J, McHale LK, Michelmore RW, Visser RGF, van de Wiel CCM (2012b) Crop to wild introgression in 
lettuce: following the fate of crop genome segments in backcross populations. BMC Plant Biol 12:43

Van de Wiel CCM, Sretenović Rajičić T, Van Treuren R, Dehmer KJ, Van der Linden CG, Van Hintum TJL (2010) Distribution of genetic diversity in wild European populations of prickly lettuce (Lactuca serriola): implications for plant genetic resources management. Plant Genet Resour Charact Util 8:171-181

Van der Arend AJM, Ester A, Van Schijndel JT (1999) Developing an aphid resistant butterhead lettuce "Dynamite". In: Lebeda A, Křístková E (eds) Eucarpia Leafy Vegetables '99 Proceedings of the Eucarpia meeting on leafy vegetables genetics and breeding, Olomouc, Czech Republic, 8-11 June 1999, Palacký University, Olomouc, pp 149-157

Van Ooijen JW (2006) JoinMap 4: software for the calculation of genetic linkage maps in experimental populations. Kyazma B.V, Wageningen
Voorrips RE (2002) MapChart: software for the graphical presentation of linkage maps and QTLs. J Hered 93:77-78

Warwick SI, Beckie HJ, Hall LM (2009) Gene flow, invasiveness, and ecological impact of genetically modified crops. Ann NY Acad Sci 1168:72-99

Wilkinson M, Tepfer M (2009) Fitness and beyond: preparing for the arrival of GM crops with ecologically important novel characters. Environ Biosaf Res 8:1-14

Yu SB, Li JX, Xu CG, Tan YF, Gao YJ, Li XH, Zhang QF, Saghai Maroof MA (1998) Epistasis plays an important role as genetic basis of heterosis in rice. Sci China Ser C Life Sci 41:293-302

Yue B, Cai X, Yuan W, Vick B, Hu J (2009) Mapping quantitative trait loci (QTL) controlling seed morphology and disk diameter in sunflower (Helianthus annuиs L.) Helia 32:17-36 